\title{
Variability in melatonin concentration in blood serum of patients with episodic migraine: a pilot study
}

\author{
Anna Zduńska ${ }^{1}$, Joanna Cegielska ${ }^{1}$, Sebastian Zduński ${ }^{2}$, Michał Białobrzewski ${ }^{1}$, Jan Kochanowski ${ }^{1}$ \\ ${ }^{1}$ Department of Neurology, Faculty of Medical Sciences, Medical University of Warsaw, Warsaw, Poland \\ ${ }^{2}$ Department of Rehabilitation, Central Clinical Hospital of the Ministry of the Interior and Administration in Warsaw, Poland
}

\begin{abstract}
Aim of study. This study was aimed at assessing the possible effect of melatonin concentration on migraine. The serum concentration profile of melatonin in patients with diagnosed episodic migraine in the interictal period was compared to the profile in patients without migraine. Then, a correlation between the frequency and duration of migraine attacks, and the possible relationship between these parameters and melatonin levels in individual patients, was established.

Clinical rationale for study. Melatonin secretion is related to migraine pathophysiology in many different ways.

Materials and methods. The study was conducted in a group of 58 subjects (48 women and 10 men). The study group comprised 29 patients ( 24 women and five men) diagnosed with migraine according to the International Classification of Headache Disorders (ICHD-3 beta), within the framework of the Outpatient Clinic at Bielanski Hospital in Warsaw and the Clinical Department of Neurology of the 2nd Faculty of Medicine (now known as the Faculty of Medical Sciences) at the Medical University of Warsaw, Poland. The control group consisted of 29 subjects ( 24 women and five men) with no headache. Blood samples for the determination of melatonin were collected at midnight, 2am, 3am, 4am and 6am. Melatonin level in a frozen serum of venous blood was determined by a radio-immuno-enzymatic method at the Department of Histology and Embryology of the Faculty of Veterinary Medicine at the University of Warmia and Mazury in Olsztyn, Poland.
\end{abstract}

Results. No statistically significant differences between the levels of melatonin and the averaged advances of melatonin profiles were observed in the examined and the control group. There were demonstrated medium negative correlations between the maximum value of melatonin and the duration of migraine $(R=-0.4, p=0.03)$. There were also observed statistically significant differences $(p=0.01)$ between the averaged advances of melatonin profiles, depending on the duration of migraine.

Conclusions and clinical implications. Our study showed no abnormalities of melatonin secretion in patients with migraine during the interictal period. The results of studies available in the literature depend on the nature of the headache (episodic or chronic) and the time of measuring the concentration of melatonin (during a headache attack or in an interictal period).

Key words: migraine, melatonin hormone, circadian rhythm, migraine pathophysiology

(Neurol Neurochir Pol 2021; 55 (1): 81-90)

\section{Introduction}

Melatonin is a hormone that allows an organism to adapt to cyclically changing environmental conditions, especially levels of light and the time of day [1]. It is produced primarily by pinealocytes, the gland cells of the pineal body [2]. The concentration of melatonin in blood results from its production, and varies during the day. It amounts to $0-20 \mathrm{pg} / \mathrm{ml}$ in the daytime but is much higher at night, reaching $40-100 \mathrm{pg} / \mathrm{ml}$ [3]. Secretion occurs at night, with maximum plasma levels around $2 \mathrm{am}$ to $4 \mathrm{am}$. The amount of melatonin produced in the pineal gland is genetically determined, and its concentration decreases with age [4].

The main centre controlling activity of the pineal body and synthesis of melatonin is the suprachiasmatic nucleus of the hypothalamus ( $\mathrm{SCN})$, which is the constituent of

Address for correspondence: Joanna Cegielska, Department of Neurology, Faculty of Medical Sciences, Medical University of Warsaw, Cegłowska 80, 01-809 Warsaw, Poland, e-mail: joanna.cegielska@wum.edu.pl 
a multiple neural pathway through which the information about changes in light conditions reaches the pineal gland [5]. The hypothalamus has also connections with trigeminal nerve nuclei, especially with caudal nucleus of the fifth nerve which is involved in migraine pathophysiology. Disorders on the retino-hypothalamic-pineal axis play a vital role in migraine pathophysiology and other spontaneous headaches [6].

Melatonin secretion is disturbed in many clinical situations. Compression of the optic chiasm due to a tumour with suprasellar extension may affect the retinohypothalamic tract and SCN, and is associated with permanent changes in total sleep duration in patients with pituitary insufficiency [7]. A large pituitary tumour exerting significant pressure on the optic chiasm disturbs the melatonin rhythm [8]. Recent studies have shown disruption of the nocturnal pick-up of melatonin in ischaemic stroke patients and in patients with acute cerebral haemorrhage. The decline in melatonin production in aged individuals has been suggested as one of the primary contributory factors for the development of age-associated neurodegenerative diseases such as Parkinson's Disease and Alzheimer's Disease. Decreased melatonin levels have also been reported in patients with some forms of epilepsy [9]. A change in the pattern of melatonin secretion has been found in various psychiatric disorders such as seasonal affective disorder, bipolar disorder, bulimia, anorexia, schizophrenia, and obsessive compulsive disorder [10]. Decreased melatonin production has been found in several cardiovascular diseases such as coronary heart disease and acute myocardial infarction. Melatonin is also probably involved in the control of the circadian rhythm of blood pressure [11].

The use of melatonin as an antihypertensive, antioxidant and anti-ischaemic drug has brought about new opportunities for the management of cardiovascular dysfunction and disease from a circadian rhythm perspective. Many investigators have been working on the hypothesis of a possible oncostatic role of melatonin on several kinds of tumours [9]. Recent studies have deepened understanding about the effects of melatonin in the management of patients with biological rhythm disorders resulting from shift work and the so-called jet-lag phenomenon. The role of melatonin and light therapy in the treatment of circadian sleep arrhythmia is currently the subject of many studies. It has been shown, for example, that sleep disturbance in many patients is caused by desynchronisation of the circadian rhythm of sleep-wake [11].

The role of melatonin in the pathophysiology of migraine is relevant in relation to its applicability in migraine therapy [12]. Melatonin has a similar structure to indomethacin, a non-steroidal anti-inflammatory drug (NSAID) belonging to indoles used for various types of headache [13]. It has been shown that melatonin $3 \mathrm{mg}$ is effective for migraine prevention, but further work is needed to determine whether there is a dose-response [14]. Melatonin receptors (MT1 and MT2) are present in the suprachiasmatic nucleus of the hypothalamus, so direct action of exogenous melatonin at the hypothalamus is possible [12]. Ongoing research on the use of melatonin agonist drugs in migraine therapy is promising, although only a few clinical trials have been conducted in patients with migraine. Effective treatment has been achieved with melatonin agonists: ramelteon (used efficiently to treat insomnia and circadian sleep disorders) [15] and agomelatine (used efficiently to treat depression) [16]. Agomelatine (in doses of $25 \mathrm{mg} /$ day for six months) decreased both the frequency and duration of migraine attacks and thus reduced the intensity of pain. It also reduced significantly the severity of depression and normalised sleep disturbances [17].

\section{Clinical rationale for this study}

Melatonin secretion is related to migraine pathophysiology in many ways. Several mechanisms are considered, including local sympathetic abnormality, hypersensitivity of the retino-hypothalamic pathway, and functional disturbance at the level of the suprachiasmatic nucleus. Since the pineal gland plays a role in the homeostatic equilibrium of the organism, low melatonin levels could reinforce the vulnerability of the rhythmic organisation of the central nervous system in migraine, and facilitate a cascade of events related to perivascular inflammation in the trigeminovascular system which also innervate the pineal gland [18].

Research over several decades has shown that melatonin is an effective antioxidant taking part in free radicals scavenging and regulation of enzymes involved in that process. Moreover, melatonin exhibits anti-inflammatory activity. For instance, it inhibits the synthesis of prostaglandin E2 which among other substances is involved in the development of perivascular neurogenic inflammation which is responsible for a migraine attack. Melatonin has also been observed to possess the ability to inhibit the enzyme of nitric oxide synthase, and to modulate the secretion of serotonin and dopamine, the substances connected with migraine pathophysiology [9].

The hypothalamus has been proposed as a central and early player in the pathophysiology of a migraine attack, as PET imaging has revealed that hypothalamic activity is altered during the 24 hours prior to pain onset, along with altered functional coupling with the spinal trigeminal nuclei and dorsal rostral pons occuring soon thereafter [19]. The occurrence of hypothalamic dysfunction may also be responsible for the appearance of migraine attacks provoked by sleep disorders, selected foods or intense light [20]. Migraine can be viewed as transient disturbances of the body's adaptive response to internal or external environmental changes. Of these factors, light is a major precipitatory or aggravating factor in attacks [18].

Sleep disturbance and migraine share a complex, and poorly understood, relationship. Patients with migraine have consistently reported poor sleep prior to migraine attacks and during them. Sleep is frequently reported to have a therapeutic role in terminating the pain of an acute migraine attack but 
occurs due to fatigue in the postdrome phase [19]. Regular sleep has been shown to be associated with a lower likelihood of having chronic migraine, and disrupted or inadequate sleep is often cited as a migraine trigger [12]. Whether insomnia is part of the migraine prodrome, or actually incites a migraine attack, is a complicated and interesting question [19].

The present study was aimed at assessing the possible effect of melatonin concentration on migraine. The serum concentration profile of this substance in patients with diagnosed migraine in the interictal period was compared to the profile in people without migraine. Then, a correlation between the frequency and duration of migraine attacks, and the possible relationship between these parameters and melatonin levels in individual patients, was established.

\section{Materials and methods}

Study design and patients

Our study was conducted in a group of 58 patients (48 women, 10 men). The study group comprised 29 patients, 24 women and five men, with a mean age of $34(\mathrm{SD}=8.8$, range: 19-50). All enrolled patients were diagnosed with episodic migraine according to the International Classification of Headache Disorders (ICHD-3 beta). There were 18 patients with migraine without aura, and 11 patients with migraine with aura. Patients were treated for migraine just for attacks. Patients did not receive any preventive treatment of migraine during the study. The characteristics of migraine patients included in the study are set out in Figures 1-5. In order

Table 1. Characteristics of groups included in study

\begin{tabular}{|c|c|c|c|c|}
\hline Parameter & $\begin{array}{c}\text { Questionnaire } \\
\text { criteria }\end{array}$ & $\begin{array}{l}\text { Migraine group } \\
\qquad(n=29)\end{array}$ & $\begin{array}{l}\text { Control group } \\
(n=29)\end{array}$ & p value \\
\hline \multirow[t]{3}{*}{ Age } & Minimum & 19 & 22 & $p=0.08^{*}$ \\
\hline & Maximum & 50 & 53 & \\
\hline & Average / SD & $34.3 / 8.8$ & $30.6 / 8.5$ & \\
\hline \multirow[t]{2}{*}{ Sex } & $\mathrm{F}$ & 24 & 24 & $p=1^{* *}$ \\
\hline & M & 5 & 5 & $p=1^{* * *}$ \\
\hline \multirow[t]{2}{*}{ Regularity of sleep hours } & Yes & 19 & 17 & $p=0.78^{* *}$ \\
\hline & No & 10 & 12 & $\mathrm{p}=0.59 * * *$ \\
\hline \multirow[t]{2}{*}{ Shift work } & Yes & 9 & 13 & $p=0.4^{* *}$ \\
\hline & No & 20 & 16 & $\mathrm{p}=0.28^{* * *}$ \\
\hline \multirow[t]{2}{*}{ Smoking } & Yes & 8 & 6 & $p=0.76^{* *}$ \\
\hline & No & 21 & 23 & $p=0.54^{* * *}$ \\
\hline \multirow[t]{2}{*}{ Alcohol abuse } & Yes & 0 & 0 & \\
\hline & No & 29 & 29 & \\
\hline
\end{tabular}

*Wilcoxon test, ${ }^{* *}$ Fisher's test, ${ }^{* * *}{ }^{*} \mathrm{Chi}^{2}$ test

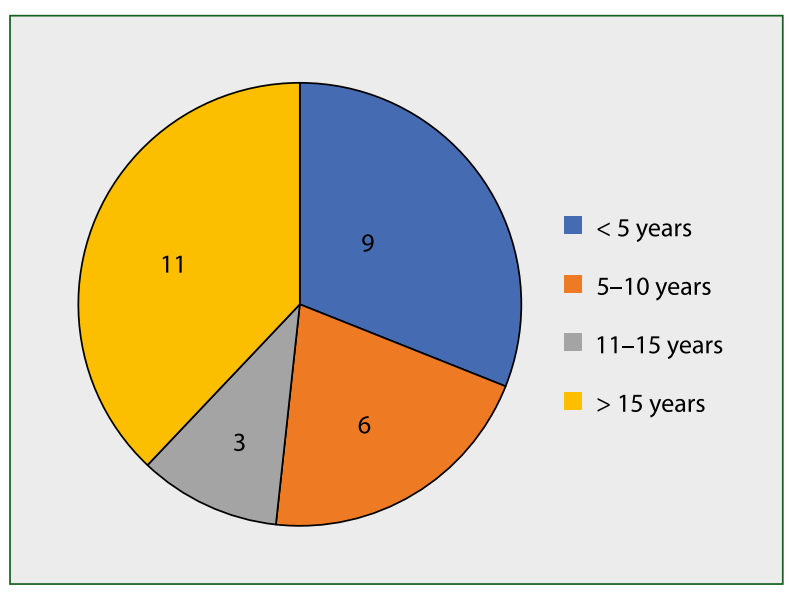

Figure 1. Duration of migraine in migraine group

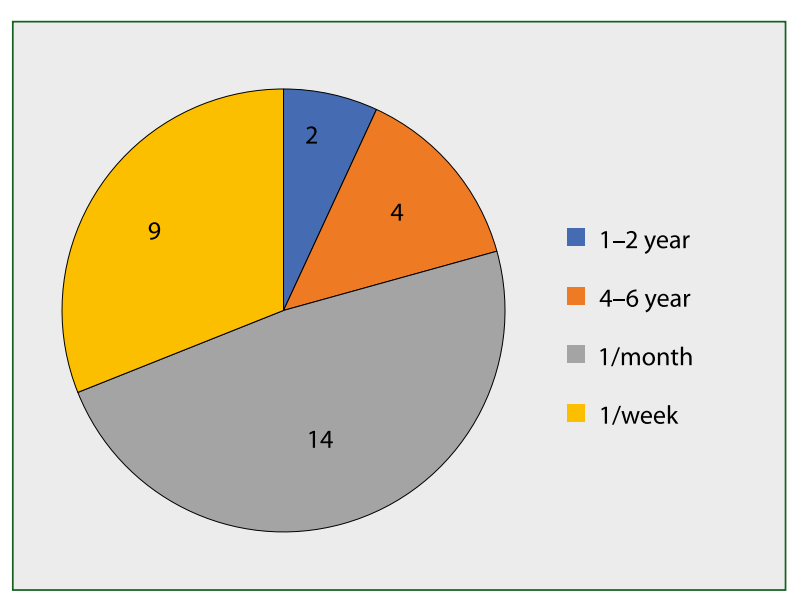

Figure 2. Frequency of migraine attacks in migraine group 


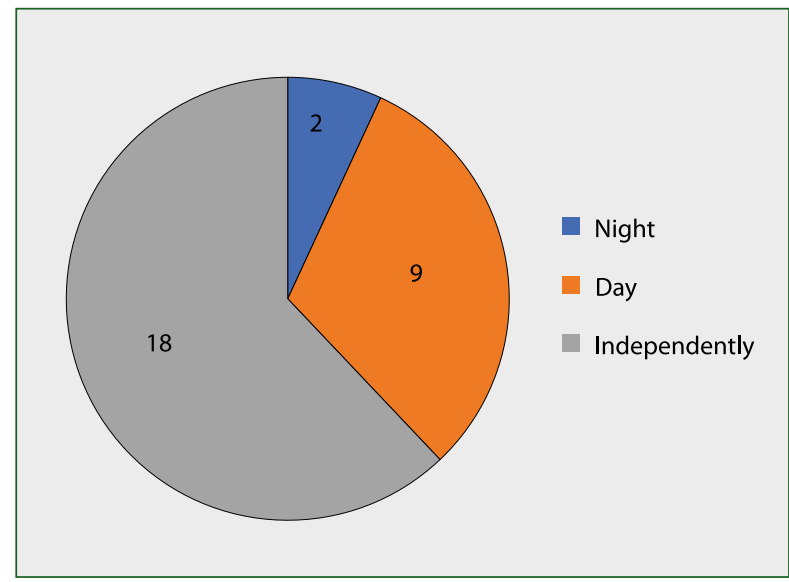

Figure 3. Time of occurrence of migraine attack during the day in migraine group

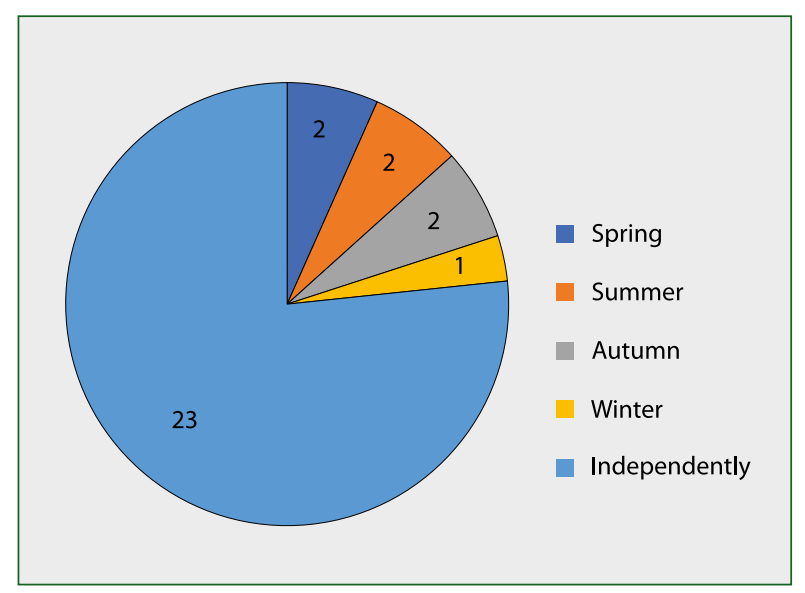

Figure 4. Dependence of migraine attack on the season of year in migraine group

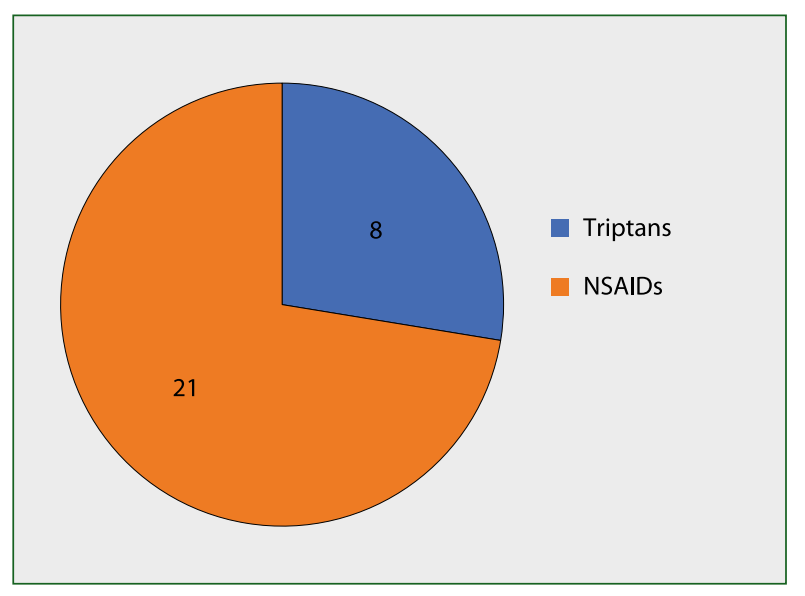

Figure 5. Drugs used during migraine attack in migraine group to exclude organic changes in the CNS, patients underwent a neurological examination and MRI brain imaging, and basic biochemical examinations. The diagnoses were performed within the framework of the Outpatient Clinic at Bielanski Hospital in Warsaw and the Clinical Department of Neurology of the 2nd Faculty of Medicine (now known as the Faculty of Medical Sciences) at the Medical University of Warsaw, Poland. Blood samples were taken in migraine patients in the interictal period, the time lapse between the last migraine attack and blood sampling being at least $24 \mathrm{~h}$.

The control group consisted of 29 subjects, 24 women and five men, with a mean age of $31(\mathrm{SD}=8.5$, range: $22-53)$ who were headache-free. There were no statistically significant differences in age, gender, regularity of sleep hours or regularity of shift work between the study group and the control group. Table 1 sets out the characteristics of the groups.

All patients ultimately qualified for the study did not have any comorbidities and did not permanently take any medication, except those used to treat migraine in the study group.

\section{Conditions for determining melatonin concentration}

Collecting blood samples for melatonin determination took place in a darkened, pre-prepared room of the Clinical Department of Neurology at Bielanski Hospital. The examined patients remained in a completely dark room from $10 \mathrm{pm}$ until 7am and in a horizontal position throughout the measurements from 9pm to $7 \mathrm{am}$. They had a cannula (outer diameter $1.2 \mathrm{~mm}$ ) inserted into a vein on the inner elbow area at $9 \mathrm{pm}$. Blood samples $(5 \mathrm{ml})$ for melatonin determination were obtained via the cannula at midnight, 2am, 3am, 4am and 6am to a plastic tube containing a clot activator, and placed on ice. The only source of light during blood collection was a darkroom lamp emitting low-powered red light. Artificial light of sufficient intensity and duration administered at night suppresses melatonin production. Light intensities of 2,000-2,500 lux for two hours (2-4am) completely suppress melatonin secretion, whereas domestic light intensities (50-300 lux) have a modestly suppressive effect. Full spectrum bright light is routinely used, but the most effective wavelengths are in the range 446-477 $\mathrm{nm}$ (blue) [4]. The use of a lamp emitting light with a longer wavelength (red) could slightly reduce melatonin secretion. However, according to most authors, light of a lower intensity than 2,500 lux does not significantly reduce melatonin production [3].

Next, the blood was spun off at 3,000 rpm for 10 minutes at $4^{\circ} \mathrm{C}$ in a centrifuge MPW $260 \mathrm{R}$. Such prepared blood serum was poured into $2 \mathrm{ml}$ Eppendorf tubes, frozen at $-20^{\circ} \mathrm{C}$ and stored in a freezer until assay.

Melatonin level in a frozen serum of venous blood was determined by a radio-immuno-enzymatic method at the 
Department of Histology and Embryology of the Faculty of Veterinary Medicine at the University of Warmia and Mazury in Olsztyn. Blood probes were frozen for transport. Concentrations of melatonin in the serum samples were based on a direct modified radioimmunological method according to Fraser et al. using G/S/704-6483 and 3-H melatonin antibodies [21]. Antibodies G/S/704-6483 and twin G/S/704-8483 are among the most commonly used in the determination of melatonin plasma levels and human blood serum. Methods of radioimmunological determination of melatonin with their use have been repeatedly authenticated, which allowed for a good characterisation of factors affecting the correctness of the results obtained.

The advantages of the method are low inter- and intra-serial variability, sufficient sensitivity, and ease of testing, while the biggest disadvantage is the need to use 500 microL plasma to perform the test in duplicate. The best kits for melatonin determination by RIA methods are kits based on G280 antibodies obtained from Kennaway. The reliability of many sets currently on the market is questionable. RIA methods are much more sensitive than U/HPLC techniques with fluorescence, electrochemical and mass spectrometry detection.

\section{Statistical methods}

Statistical analysis was performed using SAS 9.2 software. Quantitative variables were described using descriptive statistics such as mean, median, standard deviation and range. Wilcoxon Rank Sum Test for Independent Samples was used for comparing the quantitative variables of the two examined groups, as distributions of these variables showed deviations from a normal distribution. The relationship between qualitative variables was tested in contingency tables. When expected values in the table cells were not sufficiently large (i.e. above 5), it was tested with the Fisher's exact test. Spearman's rho was used to analyse the correlations between quantitative variables, because the distributions of analysed parameters were different from a normal distribution. Melatonin profiles were analysed using generalised linear mixed models (GLMM). Statistical significance was set at $\mathrm{p}<0.05$.

\section{Results}

The median of the average melatonin level in the study group was $26.98 \mathrm{pg} / \mathrm{ml}$, and $33.09 \mathrm{pg} / \mathrm{ml}$ in the control group. The median of the maximum melatonin value was $37.14 \mathrm{pg} /$ $\mathrm{ml}$ in the study group, and $55.95 \mathrm{pg} / \mathrm{ml}$ in the control group. These differences were not statistically significant: Wilcoxon test was $p=0.49$ for average melatonin values and $p=0.3$ for maximum melatonin values (Fig. 6). A comparison of both groups of patients is set out in Table 2 .

The differences in melatonin values in the control and migraine groups at individual measuring points, expressed by the quotient of means, were not statistically significant (Tab. 3). Also, there were no statistically significant differences between the levels of melatonin and the averaged advances of melatonin profiles in the groups (Fig. 7).

In both the study and the control group, the highest levels of melatonin were recorded at $3 \mathrm{am}$ : in the migraine group ( $49 \%$ of respondents) the median was $33.93 \mathrm{pg} / \mathrm{ml}$ and in the control group ( $41 \%$ of respondents) it was $47.35 \mathrm{pg} / \mathrm{ml}$. There were no statistically significant differences in the peak melatonin secretion ( $p=0.5$ in Fisher's exact test) and median values at $3 \mathrm{am}(\mathrm{p}=0.38$ in the Wilcoxon test) in the study and control group. Changes in mean melatonin values at consecutive time points in relation to the highest level were expressed as the quotient of mean values. In both the study and control groups, the increase in melatonin value from midnight to $3 \mathrm{am}$, and the decrease from $3 \mathrm{am}$ to $6 \mathrm{am}$, was statistically significant $(\mathrm{p}<0.001)$. However, the increase in melatonin value from

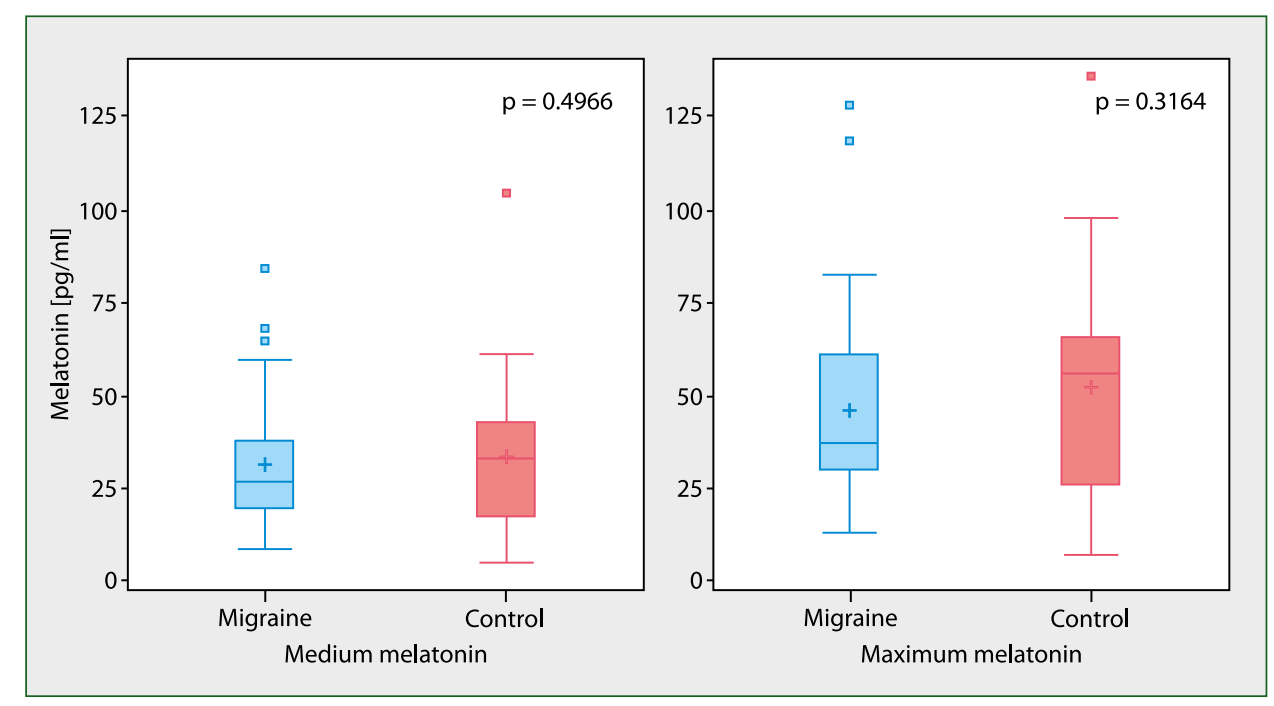

Figure 6. Comparison of melatonin concentrations in migraine and control group 
Table 2. Descriptive statistics on melatonin levels obtained in migraine group $(n=29)$ and control group $(n=29)$

\begin{tabular}{lcccccc} 
Variable & \multicolumn{5}{c}{ Descriptive statistics } \\
& Group & Average & $\begin{array}{c}\text { Standard } \\
\text { deviation }\end{array}$ & Median & Minimum & Maximum \\
\hline Melatonin 24:00 & Migraine & $21.13 \mathrm{pg} / \mathrm{ml}$ & $14.94 \mathrm{pg} / \mathrm{ml}$ & $16.95 \mathrm{pg} / \mathrm{ml}$ & $3.7 \mathrm{pg} / \mathrm{ml}$ & $58.6 \mathrm{pg} / \mathrm{ml}$ \\
& Control & $16.78 \mathrm{pg} / \mathrm{ml}$ & $14.47 \mathrm{pg} / \mathrm{ml}$ & $13.02 \mathrm{pg} / \mathrm{ml}$ & $1.39 \mathrm{pg} / \mathrm{ml}$ & $61.83 \mathrm{pg} / \mathrm{ml}$ \\
Melatonin 02:00 & Migraine & $35.19 \mathrm{pg} / \mathrm{ml}$ & $24.17 \mathrm{pg} / \mathrm{ml}$ & $29.24 \mathrm{pg} / \mathrm{ml}$ & $5.90 \mathrm{pg} / \mathrm{ml}$ & $119 \mathrm{pg} / \mathrm{ml}$ \\
& Control & $34.00 \mathrm{pg} / \mathrm{ml}$ & $24.35 \mathrm{pg} / \mathrm{ml}$ & $32.55 \mathrm{pg} / \mathrm{ml}$ & $6.77 \mathrm{pg} / \mathrm{ml}$ & $136.7 \mathrm{pg} / \mathrm{ml}$ \\
Melatonin 03:00 & Migraine & $42.69 \mathrm{pg} / \mathrm{ml}$ & $25.59 \mathrm{pg} / \mathrm{ml}$ & $33.93 \mathrm{pg} / \mathrm{ml}$ & $12.81 \mathrm{pg} / \mathrm{ml}$ & $128.24 \mathrm{pg} / \mathrm{ml}$ \\
& Control & $46.78 \mathrm{pg} / \mathrm{ml}$ & $28.86 \mathrm{pg} / \mathrm{ml}$ & $47.35 \mathrm{pg} / \mathrm{ml}$ & $5.08 \mathrm{pg} / \mathrm{ml}$ & $137.93 \mathrm{pg} / \mathrm{ml}$ \\
Melatonin 04:00 & Migraine & $37.69 \mathrm{pg} / \mathrm{ml}$ & $22.91 \mathrm{pg} / \mathrm{ml}$ & $33.04 \mathrm{pg} / \mathrm{ml}$ & $7.06 \mathrm{pg} / \mathrm{ml}$ & $105.63 \mathrm{pg} / \mathrm{ml}$ \\
& Control & $45.2 \mathrm{pg} / \mathrm{ml}$ & $25.71 \mathrm{pg} / \mathrm{ml}$ & $46.12 \mathrm{pg} / \mathrm{ml}$ & $7.05 \mathrm{pg} / \mathrm{ml}$ & $103.05 \mathrm{pg} / \mathrm{ml}$ \\
Melatonin 06:00 & Migraine & $20.64 \mathrm{pg} / \mathrm{ml}$ & $15.51 \mathrm{pg} / \mathrm{ml}$ & $19.19 \mathrm{pg} / \mathrm{ml}$ & $1.75 \mathrm{pg} / \mathrm{ml}$ & $65.23 \mathrm{pg} / \mathrm{ml}$ \\
& Control & $25.48 \mathrm{pg} / \mathrm{ml}$ & $20.9 \mathrm{pg} / \mathrm{ml}$ & $21.83 \mathrm{pg} / \mathrm{ml}$ & $2.99 \mathrm{pg} / \mathrm{ml}$ & $82.96 \mathrm{pg} / \mathrm{ml}$ \\
Melatonin average & Migraine & $31.47 \mathrm{pg} / \mathrm{ml}$ & $18.58 \mathrm{pg} / \mathrm{ml}$ & $26.98 \mathrm{pg} / \mathrm{ml}$ & $8.68 \mathrm{pg} / \mathrm{ml}$ & $84.53 \mathrm{pg} / \mathrm{ml}$ \\
& Control & $33.65 \mathrm{pg} / \mathrm{ml}$ & $20.66 \mathrm{pg} / \mathrm{ml}$ & $33.09 \mathrm{pg} / \mathrm{ml}$ & $5.09 \mathrm{pg} / \mathrm{ml}$ & $104.49 \mathrm{pg} / \mathrm{ml}$ \\
Melatonin max & Migraine & $46.21 \mathrm{pg} / \mathrm{ml}$ & $27.58 \mathrm{pg} / \mathrm{ml}$ & $37.14 \mathrm{pg} / \mathrm{ml}$ & $12.81 \mathrm{pg} / \mathrm{ml}$ & $128.24 \mathrm{pg} / \mathrm{ml}$ \\
& Control & $52.16 \mathrm{pg} / \mathrm{ml}$ & $30.57 \mathrm{pg} / \mathrm{ml}$ & $55.95 \mathrm{pg} / \mathrm{ml}$ & $7.05 \mathrm{pg} / \mathrm{ml}$ & $137.93 \mathrm{pg} / \mathrm{ml}$
\end{tabular}

Table 3. Comparison of average values at individual measuring points between groups

\begin{tabular}{lllcl} 
& \multicolumn{4}{c}{ Comparison of mean values between groups } \\
Time & Time from & Time to & Quotient of means & p-value \\
\hline 24:00 & Control group & Migraine group & 0.7937 & 0.2026 \\
$02: 00$ & Control group & Migraine group & 0.9661 & 0.8491 \\
$03: 00$ & Control group & Migraine group & 1.0957 & 0.6137 \\
$04: 00$ & Control group & Migraine group & 1.1992 & 0.3160 \\
$06: 00$ & Control group & Migraine group & 1.2347 & 0.2448 \\
\hline
\end{tabular}

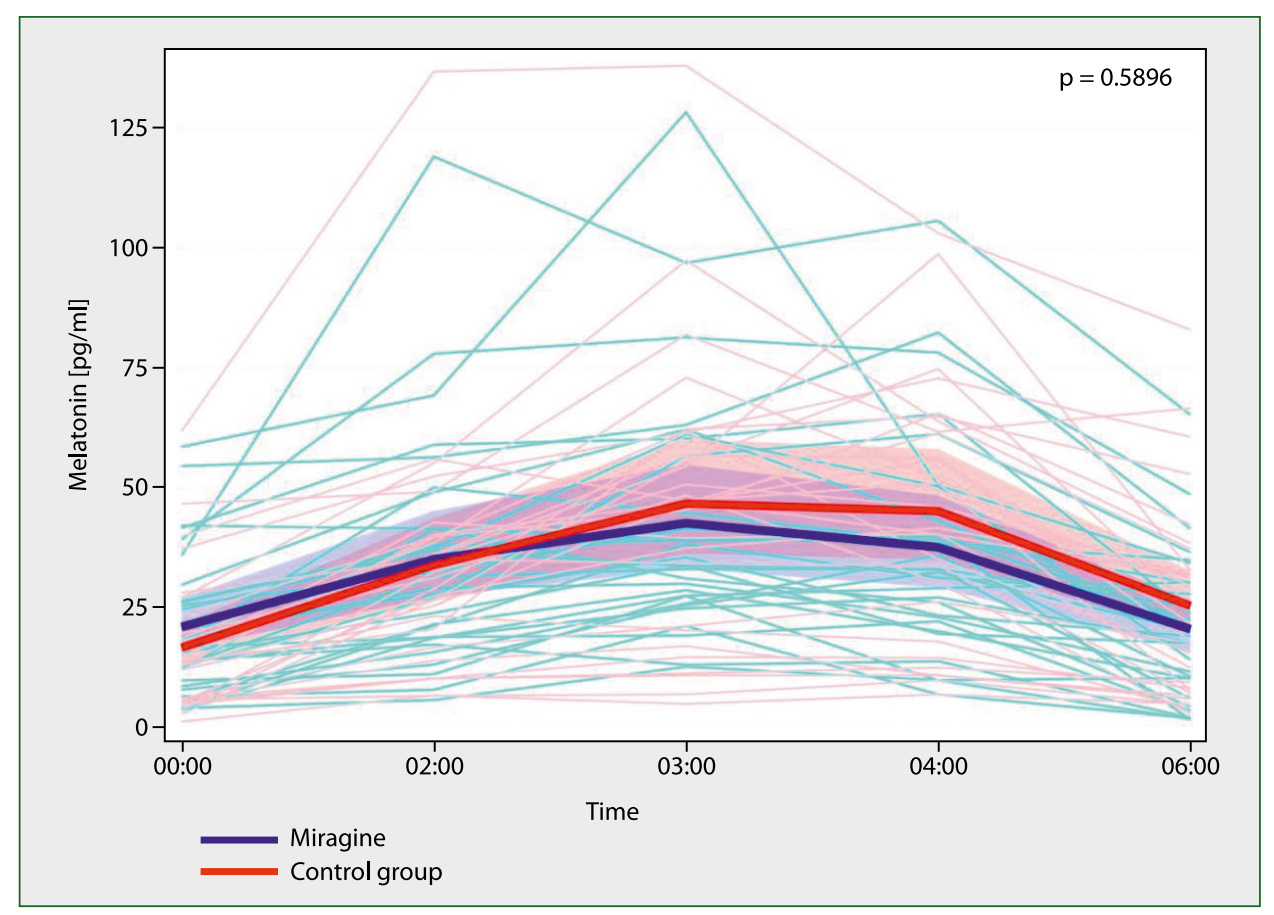

Figure 7. Comparison of melatonin profiles in migraine and control groups 


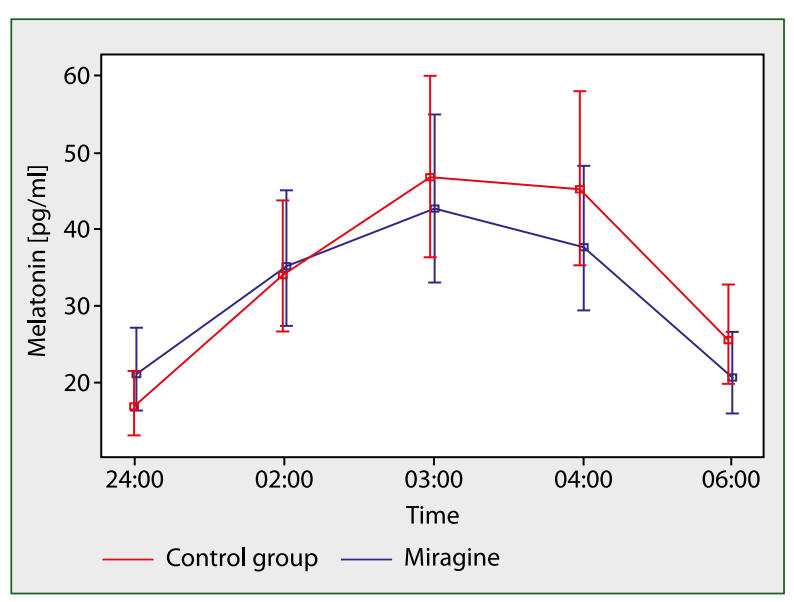

Figure 8. Changes in mean melatonin values at subsequent time

2am to $3 \mathrm{am}$ and the decrease from $3 \mathrm{am}$ to $4 \mathrm{am}$ did not show statistical significance in both groups (Fig. 8, Tab. 4).

The relationship between melatonin concentration and duration of migraine was assessed with the Spearman's rank correlation. There were medium negative correlations between the maximum value of melatonin and the duration of migraine $(\mathrm{R}=-0.4, \mathrm{p}=0.03)$. Moreover, there were observed statistically significant differences $(p=0.01)$ between the averaged advances of melatonin profiles, depending on the duration of migraine. Melatonin values forming the profile were statistically higher in the group of patients with a short migraine history $(<$ 10 years) than in the group with long migraine history ( $\geq 10$ years) (Fig. 9). At the same time, the patients with migraines lasting more than 10 years were not significantly older than those with a shorter migraine duration $(\mathrm{p}=0.053)$.

There were no statistically significant correlations between the frequency of migraine attacks and the values of melatonin: medium $(R=-0.1, p=0.6)$ and maximum $(R=-0.1, p=0.6)$.

No statistically significant differences were observed between the migraine group with and without aura (Fig. 10).

\section{Conclusions and clinical implications}

The conducted study showed no statistically significant differences between the values of melatonin concentrations in individual measurements of the study and control group. Furthermore, no statistically important interactions between melatonin profiles of the study and control group were observed. Medians of melatonin values were lower in the study group than in the control group, but the differences were not statistically significant. Similarly, study group patients had slightly lower ratings in the averaged advances of melatonin profiles than the control group, but again the differences were not significant. Given this, only a tendency towards lower melatonin levels in migraine patients can be discussed.
Table 4. Changes in mean melatonin values at subsequent time points relative to highest level

\begin{tabular}{lccc|}
\hline Group & $\begin{array}{c}\text { Time from } \\
\text { peak melatonin } \\
\text { to }\end{array}$ & $\begin{array}{c}\text { Quotient } \\
\text { of means }\end{array}$ & p-value \\
\hline $\begin{array}{l}\text { Control } \\
\text { group }\end{array}$ & $24: 00$ & 2.789 & $<0.001$ \\
& $02: 00$ & 1.376 & 0.079 \\
& $04: 00$ & 1.035 & 0.849 \\
& $06: 00$ & 1.836 & $<0.001$ \\
Migraine & $24: 00$ & 2.021 & $<0.001$ \\
group & $02: 00$ & 1.213 & 0.286 \\
& $04: 00$ & 1.133 & 0.491 \\
& $06: 00$ & 2.069 & $<0.001$ \\
\hline
\end{tabular}

One of the first studies on melatonin concentration in migraine patients, conducted in 1989 by Claustrat et al., showed a lower level of melatonin in serum obtained at $11 \mathrm{pm}$ from migraine patients compared to serum of the control group. Additionally, that level was lower in patients with migraine and comorbid depression than in a migraine group without depression [22]. Brun et al. studied the correlation between melatonin concentration and menstrual cycle phases in patients suffering from menstrual migraine. The melatonin concentration was lower in migraine patients than in the control group. It was noted that when compared to the interictal period, the melatonin concentration during migraine attacks was much lower. However, there was observed no connection between the time and intensity of a headache and melatonin concentration [23].

In the study conducted on a group of menstrual migraine patients by Murialdo et al., melatonin concentrations were measured from urine samples collected during the day and at night. The concentration of melatonin was much lower in the urine of patients than in the urine of a control group (both during the day and at night). Also, when compared to the interictal period, the melatonin concentration in patients during migraine attacks was lower [24].

In the study conducted in 2001 by Peres et al., the circadian rhythm of melatonin secretion in patients with chronic migraine was assessed by measuring melatonin concentration in serum between $7 \mathrm{pm}$ and $7 \mathrm{am}$. Unlike the control group, the group of chronic migraine patients had a delay in the nocturnal peak of melatonin secretion. However, no statistically important difference in melatonin concentration between the study and the control group was found. Patients with chronic migraine and comorbid insomnia have a considerably lower level of melatonin [25]. However, the results of a study conducted in 2006 by Masruha et al. on a group of 146 patients with migraine (episodic and chronic) were different. The concentration of melatonin metabolite 6-Sulfatoxymelatonin was determined 


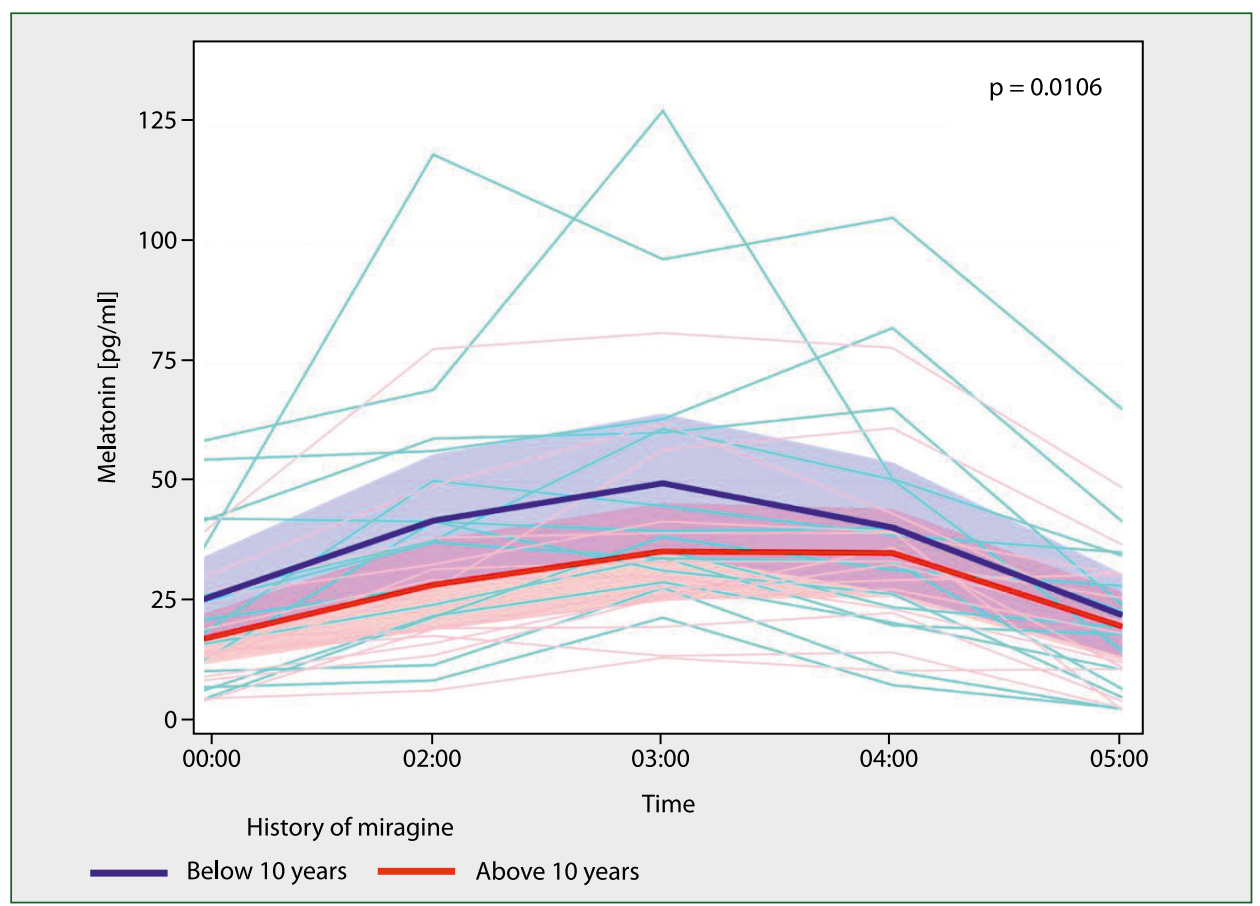

Figure 9. Comparison of melatonin profiles depending on duration of migraine in study group $(n=15$ for group with history of migraine $<10$ years, $n=14$ for group with history of migraine $>10$ years)

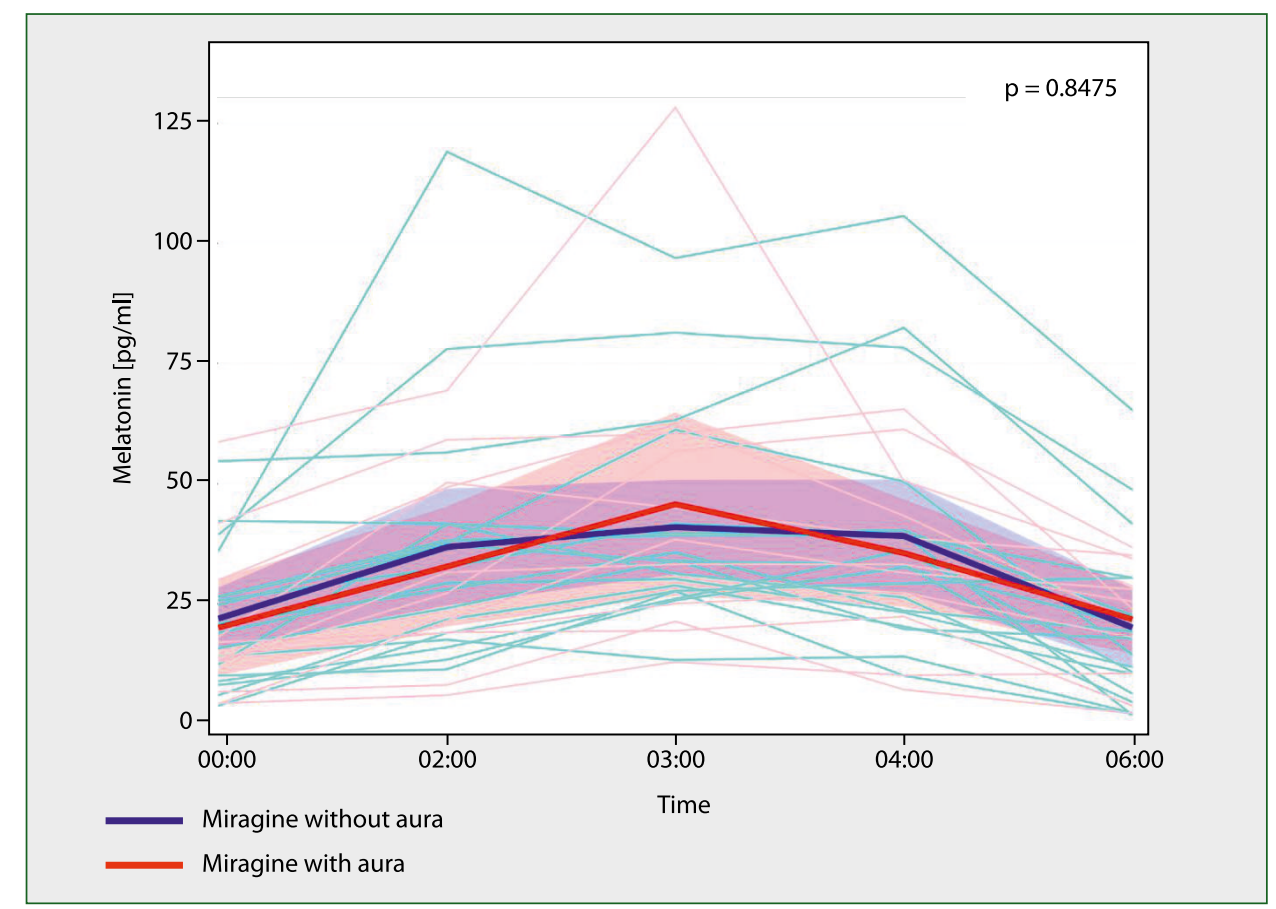

Figure 10. Comparison of melatonin profiles in migraine groups with and without aura $(n=18$ for migraine without aura group, $n=11$ for migraine with aura group)

by the ELISA method in nocturnal urine samples (collected between $8 \mathrm{pm}$ and $8 \mathrm{am}$ ). No differences in melatonin concentration between the study group in the interictal period and the non-headache control group were found. A considerably lower concentration of melatonin was recorded in patients who developed a migraine attack during the assay ( $53 \%$ of patients) than in patients in the interictal period and the control group. Moreover, there were no significant differences in melatonin 
concentration in patients with migraine aura $(24 \%)$ compared to those without it, and in the group with episodic and chronic migraine [26].

In 2017, Kozak et al. published a study in which sleep quality and melatonin levels were assessed in migraine patients compared to a control group. The study was conducted in a group of 55 migraine patients compared to 57 people without headache. Blood samples were taken from all participants at about lam and blood melatonin levels were measured using the ELISA test. The time lapse between the last migraine attack and blood sampling was at least $48 \mathrm{~h}$. It was observed that the level of melatonin was statistically significantly lower in the migraine patients compared to the control group [27].

According to literature reports, the melatonin level in migraine patients is variable and depends on many factors. No doubt the size and selection of a group is of great importance. The results depend also on the nature of the headache (episodic or chronic) and the time of measuring the concentration of melatonin (during a headache attack or an interictal period). In several studies cited, just as in ours, there were no statistically significant differences between melatonin concentration in patients with migraine in the interictal period and in a control group. We expected that migraine patients would have lower melatonin levels in the interictal period, which could have an impact on their treatment. However, no such connections were obtained. Therefore, our study has mainly cognitive and didactic values.

The basic limitation of our study is the small number of patients qualified for the study. It would be advisable to conduct a study on a larger group of patients and to plan the tests also during a migraine attack, and to compare the results in a migraine group during a migraine attack and in the interictal period. Another limitation of our study is the lack of information on the severity of migraine (measured using MIDAS or HIT scales).

How do we explain the fact that low concentrations of melatonin metabolite can be found only in the group of patients with migraine attacks during the assay?

It is probable that hypothalamic dysfunction takes place only during a migraine attack and in the prodromal phase. Therefore, the concentration of melatonin in the interictal period does not decrease. We can also assume that all migraine patients have a reduced melatonin level, whilst patients in the interictal period have their melatonin level adequately increased.

These observations highlight the important role of the hypothalamus in the pathophysiology of migraine [28]. It should be noted that several studies have shown reduced melatonin concentration only in patients diagnosed with chronic migraine. Perhaps only chronic, persistent headache typical of migraine or attacks of a frequency increasing over time disrupt the function of the hypothalamus, and have an inhibitory effect on melatonin secretion. Moreover, these observations can be confirmed by our results. Namely, our study showed a statistically significant negative correlation between the maximum melatonin level and the duration of migraine in the study group. We also observed a statistically important interaction between the profiles of melatonin, depending on the duration of migraine. Patients with a migraine history of longer than 10 years achieved considerably lower advance of melatonin profiles than did those with shorter migraine history.

Perhaps a longer course of migraine, and a connected greater frequency of attacks, influence the reduction of melatonin secretion [29].

Ethical permission: This study was approved by the Bioethics Committee of the Medical University of Warsaw. All participants were fully informed of the purpose and means of conducting the examinations, and gave their written consent to participate.

Funding: This publication was prepared without any external source of funding.

Conflicts of interest: None.

\section{References}

1. Gelfand AA, Goadsby PJ. The Role of Melatonin in the Treatment of Primary Headache Disorders. Headache. 2016; 56(8): 1257-1266, doi: 10.1111/head.12862, indexed in Pubmed: 27316772.

2. Meng X, Li Ya, Li S, et al. Dietary Sources and Bioactivities of Melatonin. Nutrients. 2017; 9(4), doi: 10.3390/nu9040367, indexed in Pubmed: 28387721.

3. Słowińska-Klencka D, Lewiński A. Rola melatoniny w fizjologii i patologii człowieka. I. Dobowy rytm wydzielania melatoniny. Znaczenie melatoniny w fizjologii rozrodu. Melatonina a oś podwzgórze - przysadka - kora nadnerczy. Postępy Higieny i Medycyny Doświadczalnej. 1993; 47(3): 209-220.

4. Claustrat B, Leston J. Melatonin: Physiological effects in humans. Neurochirurgie. 2015; 61(2-3): 77-84, doi: 10.1016/j.neuchi.2015.03.002, indexed in Pubmed: 25908646.

5. Emens JS, Burgess HJ. Effect of Light and Melatonin and Other Melatonin Receptor Agonists on Human Circadian Physiology. Sleep Med Clin. 2015; 10(4): 435-453, doi: 10.1016/j.jsmc.2015.08.001, indexed in Pubmed: 26568121.

6. Deshmukh VD. Retino-hypothalamic-pineal hypothesis in the pathophysiology of primary headaches. Med Hypotheses. 2006; 66(6): 1146-1151, doi: 10.1016/j.mehy.2005.12.026, indexed in Pubmed: 16530980.

7. Borgers AJ, Romeijn N, van Someren E, et al. Compression of the optic chiasm is associated with permanent shorter sleep duration in patients with pituitary insufficiency. Clin Endocrinol (Oxf). 2011; 75(3): 347-353, doi: 10.1111/j.1365-2265.2011.04053.x, indexed in Pubmed: 21521321.

8. Zielonka D, Sowiński J, Nowak S, et al. Melatonin and cortisol profiles in patients with pituitary tumors. Neurol Neurochir Pol. 2015; 49(1): 65-69, doi: 10.1016/j.pjnns.2014.12.004, indexed in Pubmed: 25666777.

9. Altun A, Ugur-Altun B. Melatonin: therapeutic and clinical utilization. Int J Clin Pract. 2007; 61(5): 835-845, doi: 10.1111/j.1742-1241.2006.01191.x, indexed in Pubmed: 17298593. 
10. Pacchierotti C, lapichino S, Bossini L, et al. Melatonin in psychiatric disorders: a review on the melatonin involvement in psychiatry. Front Neuroendocrinol. 2001; 22(1): 18-32, doi: 10.1006/ frne.2000.0202, indexed in Pubmed: 11141317.

11. Lewiński A, Karbownik-Lewińska M. Znaczenie kliniczne i zastosowanie terapeutyczne melatoniny - obecny stan wiedzy. Folia Medica Lodziensia 2010; 37. ; 1: 111-150.

12. Gelfand AA, Goadsby PJ. The Role of Melatonin in the Treatment of Primary Headache Disorders. Headache. 2016; 56(8): 1257-1266, doi: 10.1111/head.12862, indexed in Pubmed: 27316772.

13. Singh M, Jadhav HR. Melatonin: functions and ligands. Drug Discov Today. 2014; 19(9): 1410-1418, doi: 10.1016/j.drudis.2014.04.014, indexed in Pubmed: 24792719.

14. Gonçalves AL, Martini Ferreira A, Ribeiro RT, et al. Randomised clinical trial comparing melatonin $3 \mathrm{mg}$, amitriptyline $25 \mathrm{mg}$ and placebo for migraine prevention. J Neurol Neurosurg Psychiatry. 2016; 87(10): 1127-1132, doi: 10.1136/jnnp-2016-313458, indexed in Pubmed: 27165014.

15. Hou YC, Lai CH. The Relief Effects of Ramelteon on Refractory Chronic Migraine: A Case Report. Clin Psychopharmacol Neurosci. 2016; 14(4): 405-406, doi: 10.9758/cpn.2016.14.4.405, indexed in Pubmed: 27776398.

16. Guglielmo R, Martinotti G, Di Giannantonio M, et al. A possible new option for migraine management: agomelatine. Clin Neuropharmacol. 2013; 36(2): 65-67, doi: 10.1097/WNF.0b013e3182800271, indexed in Pubmed: 23503551.

17. Srinivasan V, Lauterbach EC, Ho KYu, et al. Melatonin in antinociception: its therapeutic applications. Curr Neuropharmacol. 2012; 10(2): 167-178, doi: 10.2174/157015912800604489, indexed in Pubmed: 23204986.

18. Claustrat B, Brun J, Chazot G. The basic physiology and pathophysiology of melatonin. Sleep Med Rev. 2005; 9(1): 11-24, doi: 10.1016/j. smrv.2004.08.001, indexed in Pubmed: 15649735.

19. Vgontzas A, Pavlović JM. Sleep Disorders and Migraine: Review of Literature and Potential Pathophysiology Mechanisms. Headache. 2018;
58(7): 1030-1039, doi: 10.1111/head.13358, indexed in Pubmed: 30091160.

20. Alstadhaug KB. Migraine and the Hypothalamus. Cephalalgia. 2009; 29(8): 809-817, doi: 10.1111/j.1468-2982.2008.01814.x.

21. Fraser $S$, Cowen $P$, Franklin $M$, et al. Direct radioimmunoassay for melatonin in plasma. Clin Chem. 1983; 29(2): 396-397, indexed in Pubmed: 6821961.

22. Peres MFP, Masruha MR, Zukerman E, et al. Potential therapeutic use of melatonin in migraine and other headache disorders. Expert Opin Investig Drugs. 2006; 15(4): 367-375, doi: 10.1517/13543784.15.4.367, indexed in Pubmed: 16548786.

23. Gagnier JJ. The therapeutic potential of melatonin in migraines and other headache types. Altern Med Rev. 2001; 6(4): 383-389, indexed in Pubmed: 11578254.

24. Murialdo G, Fonzi S, Costelli P, et al. Urinary melatonin excretion throughout the ovarian cycle in menstrually related migraine. Cephalalgia. 1994; 14(3): 205-209, doi: 10.1046/j.1468-2982.1994.014003205.x, indexed in Pubmed: 7954740.

25. Peres MF, Sanchez del Rio M, Seabra ML, et al. Hypothalamic involvement in chronic migraine. J Neurol Neurosurg Psychiatry. 2001; 71(6): 747-751, doi: 10.1136/jnnp.71.6.747, indexed in Pubmed: 11723194.

26. Masruha MR, de Souza Vieira DS, Minett TS, et al. Low urinary 6-sulphatoxymelatonin concentrations in acute migraine. J Headache Pain. 2008; 9(4): 221-224, doi: 10.1007/s10194-008-0047-5, indexed in Pubmed: 18594760.

27. Kozak HH, Boysan M, Uca AU, et al. Sleep quality, morningness-eveningness preference, mood profile, and levels of serum melatonin in migraine patients: a case-control study. Acta Neurol Belg. 2017; 117(1): 111-119, doi: 10.1007/s13760-016-0723-1, indexed in Pubmed: 27858294.

28. Alstadhaug KB. Migraine and the Hypothalamus. Cephalalgia. 2009; 29(8): 809-817, doi: 10.1111/j.1468-2982.2008.01814.x.

29. Bruera 0, Sances G, Leston J, et al. Plasma melatonin pattern in chronic and episodic headaches: evaluation during sleep and waking. Funct Neurol. 2008; 23(2): 77-81, indexed in Pubmed: 18671907. 